NOTICE: this is the author's version of a work that was accepted for publication in International Review of Financial Analysis. Changes resulting from the publishing process, such as peer review, editing, corrections, structural formatting, and other quality control mechanisms may not be reflected in this document. Changes may have been made to this work since it was submitted for publication. A definitive version was subsequently published in International Review of Financial Analysis, Vol. 37 (2015). DOI: 10.1016/j.irfa.2014.11.019 


\section{Time-variation in the impact of news sentiment}

Lee A. Smales, CFA

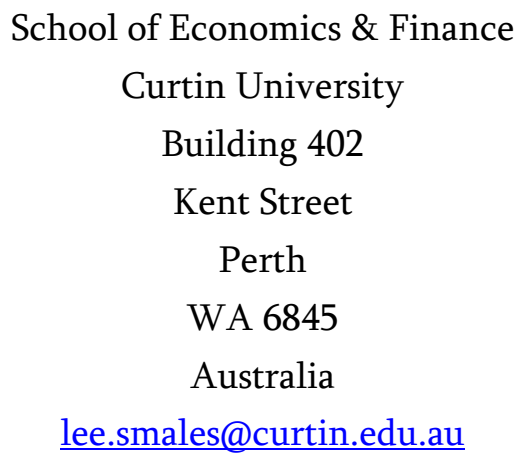

Utilising firm-specific news sentiment data provided by Thomson Reuters News Analytics, I construct aggregate measures to examine the relationship between news sentiment and stock market returns over the period 2004-2010. I find a highly significant relationship between aggregated measures of news sentiment and stock returns that fluctuates by time and by industry. I identify a link between the time-variation of news sentiment impact and industry beta, and determine that levels of investor sentiment (proxied by VIX) play an important role in explaining this variation.

JEL Codes: G10; G12; G14

Acknowledgements: I would like to thank seminar participants at Curtin University, and the Asian Finance Association Conference (2013) for constructive and helpful comments. I would also like to gratefully acknowledge the financial support from the Curtin Business School journal publication support fund. 


\section{Introduction}

Investors have been interested in the impact of information arrival for centuries; with news potentially inducing large changes in stock prices and thus creating market uncertainty and opportunity for profit. Modern investors are faced with an ever-increasing range of news that contains noise and is difficult to process; as the sentiment of investors' changes then it is also likely that they will place different levels of importance on particular news items. I am motivated to discover how the relationship between news and market returns changes over time, and what might cause this change.

A significant body of work has identified that the arrival of news can drive movements in stock prices and volatility. Initial research focused on specific and easily identifiable news events such as dividend announcements and earnings results. However, advancement in technology and the quantification of news language (e.g. Tetlock 2007; Tetlock et al. 2008) has enabled the study of market reactions across a wider range of events. In particular, the relevance and sentiment of news has been tested in a variety of market settings. Tetlock et al. (2008) find that a quantitative measure of language can predict firms' earnings and stock returns, while Dzielinski (2011) asserts that positive (negative) news results in above (below) average returns. The availability of news analytics tools, with pre-processed sentiment indicators, is part of the information revolution that Leinweber and Sisk (2011) identify as been underway in trading and investing, and has enabled the extension of news sentiment analysis to a wider variety of news events. Garcia (2013) reports that sentiment based on market-level news can predict returns, but the effect is concentrated in recessionary periods.

The capital asset pricing model (CAPM) of Sharpe (1964) and Lintner (1965), augmented by the risk factors of Fama and French $(1992,1993)$ and Carhart's (1997) momentum has long been a guiding principle for investors and portfolio managers in determining expected returns for particular stocks and portfolios of risky assets, at least in part owing to its simplicity. However, there is compelling evidence that beta stationarity, a central assumption of CAPM, does not hold true. Bos and Newbold (1984) suggest that time-variation in beta may be due to both macroeconomic and / or microeconomic factors. To-date little attempt has being made at reconciling the time-variation of beta with the time-variation of news sentiment effects. 
I contribute to the extant literature in three important ways. First, I explicitly consider timevariation in industry-specific news sentiment measures for the first time. Second, I investigate the possibility of a link between the time-variation of industry-specific news sentiment effects and beta; this is particularly related to Fama and French (1997) who note a strong variation through time in the risk factor loadings of various industries. Third, by utilising the CBOE's Implied Volatility (VIX) measure as a proxy for investor sentiment I am able to explore the importance of investor fear in determining the response to news in a wider variety of circumstances than considering only periods of recession.

Using a sample of 3,810,335 novel, and highly relevant, news items I find a highly significant relationship between aggregated measures of industry-specific news sentiment and industry stock returns. Consistent with the extant literature this relationship is asymmetric such that the magnitude of response to negative news is greater; however, when the level of investor fear is low the response to negative news is insignificant at an industry level. I conclude that the news return relationship is time-varying in nature, and identify a link between the time-variation in the impact of news sentiment and industry beta. Finally, I am able to determine that levels of investor sentiment play an important role in shaping the news sentiment - market return relationship; in particular, when investor fear is high the firm specific news appears to play little part in determining returns, it is likely that during such periods systemic news plays the dominant role in the minds of investors. While the analysis is focused on the U.S. market the results have broader implications for the news-sentiment - market return relationship on an international basis and across asset classes.

\section{Related Literature}

\subsection{News sentiment and contextual analysis}

Antweiler and Frank (2004) were the first to apply contextual analysis and develop news sentiment measures to understand stock returns; using a Naïve Bayes algorithm to assign trading signals on the basis of messages posted to internet message boards they find that while such messages are able to predict market volatility, their effect on stock returns while statistically significant is economically small. In a similar context, Zhang et al. (2012) incorporate several methodological improvements in order to create news sentiment indices that are significant directional indicators. 
Tetlock (2007) undertakes a different approach that has become more prevalent in the literature; classifying words on the basis of categories from the Harvard psychosocial dictionary, he assigns quantitative scores to content in the Wall Street Journal's "Abreast of the Market" column and reports that high levels of media pessimism predict declining market prices which are followed by price reversals. Using a similar methodology, Engelberg (2008) and Tetlock et al. (2008) find that the proportion of negative words in a news story forecasts firm earnings, reporting that this is due to the linguistic content of news messages capturing hard to quantify aspects of fundamentals which are quickly impounded into stock prices.

Advances in technology have enabled the development of news analytics software packages, such as Thomson Reuters News Analytics (TRNA) and Ravenpack which utilize advanced algorithms to assign sentiment indicators to a multitude of firm-specific newswire releases; this moves textual analysis in "real-time" and enables investors willing to pay for the service to employ such technology in quantitative trading strategies. This software has also been applied in an academic setting, enabling application in a high-frequency setting: Groß-Klußmann (2011) and Smales (2014a) note that the classification of news according to indicated relevance is crucial for noise filtering and identification of significant effects, with high-relevance news inducing an increase in both market activity and volatility. Dzielinski (2011, 2012) and Smales (2014b) use TRNA sentiment scores to create aggregate daily news sentiment measures; they report that positive news results in above average returns, negative news induces below average returns, and neutral news days are indistinguishable from days with no-news.

The news sentiment literature also reports evidence of an asymmetric reaction to news such that negative news has a greater impact on returns and volatility than does positive news; for example Groß-Klußmann (2011), Leinweber and Sisk (2011), and Smales (2014) find a more vigorous reaction to negative news, while Tetlock et al. (2008) focuses on the ability of negative words in news articles to forecast earning and lower the stock price. Riordan et al. (2013) suggest that negative news messages are associated with higher adverse selection costs, are more informative, and induce stronger market reactions.

Essentially, one branch of the extant literature has focused on the impact of general market news reported in newspaper columns, while the other has focused on firm-specific news quantified by news analytics software; in neither case is the association with risk premia a focus, and in general industry level responses are ignored. 


\subsection{Time-variation of news impact on market returns}

Since Mindell $\left(1961^{1}\right)$ noted that the market "often responds differently to the same type of news on different occasions", there has been a plethora of research seeking to investigate why this may be. Several authors (Kandel and Stambaugh, 1990; McQueen and Roley, 1993; Boyd et al., 2005; Knif et al., 2008, Kurov, 2010) note the relative importance of macroeconomic news changes over time conditional on the state of the economy. In particular, recession appears to create heightened sensitivity to news which results in more volatile stock market reactions (Hamilton and Lin, 1998; Bashishta and Kurov, 2008). Garcia (2013) studies the effect of news sentiment measures on the Dow Jones Industrial Average (DJIA) over the course of a century and finds that the predictability of stock returns using news content is concentrated in recessions.

Although a number of authors have considered the time-variant nature of the relationship between asset prices and macroeconomic news only Garcia (2013) has considered the time variation with news sentiment measures derived from contextual analysis. To-date, the extant literature has failed to examine both the time-varying influence of firm-specific and industrylevel news sentiment measures on stock market returns, and any relationship with other risk factors.

\subsection{Time variation of beta}

The asset-pricing model of Sharpe (1964) and Lintner (1965) has shaped the field of empirical asset finance over the course of the last 50 years. Fama and French $(1992,1993)$ extended this model with the identification of common risk factors in the returns on stocks: an overall market risk factor (Beta) and factors related to firm size (SML) and book-to-market equity (HML). Subsequently, Carhart (1997) introduced a fourth, momentum (MOM) factor.

However, there is considerable evidence that one of the central tenants of this theory, beta stability, is invalid: Fabozzi and Francis (1978), Bos and Newbold (1984) and Kim (1993) provide evidence of this in a U.S. context, while Brooks, Faff and Lee $(1992,1994)$ and Brooks, Faff and McKenzie (1998) demonstrate this is also true in an international context. Bolleslev, Engle and Wooldridge (1998) propose that this time-varying risk premia is a result of conditional variances varying over time, while Durand et al. (2011) suggest that the phenomenon is a result of investors fear, captured by expectations of total market risk, encapsulated in VIX . The notion of investor

\footnotetext{
${ }^{1}$ Although the article was published in 1961, the comments originated in 1945.
} 
fear affecting beta is taken up by Choudhry (2005a, 2005b), Choudhry et al. (2010) and Durand et al. (2014) who demonstrate that terrorist attacks and the Asian financial crisis impact the risk factors, and beta in particular, of a range of U.S. and international stocks.

The current literature has made an attempt to explain the time-varying nature of the beta of a risky asset with reference to changes in investor sentiment, particularly during times of crisis. However, a complementary explanation may also exist by considering the evolving nature of investor response to news sentiment, and as yet this link between beta and news sentiment has not been explored.

\section{Data}

\subsection{News Sentiment Indicators}

News sentiment data for the period $2^{\text {nd }} J a n u a r y ~ 2004-31^{\text {st }}$ December 2010 (1,742 trading days) is obtained from Thomson Reuters News Analytics (TRNA) ${ }^{2}$ for all stocks traded on the New York Stock Exchange (NYSE), NASDAQ and American Stock Exchange (AMEX). The TRNA data set describes each news item with more than 40 pieces of metadata, with the most important in the context of this investigation being:

- Identifier of the company mentioned in the news;

- Timestamp, indicating the arrival of the news article to precision of 1-sec;

- Sentiment, a discrete variable indicating whether the news was positive $(+1)$, neutral $(0)$ or negative (-1). This measure is based on a purely linguistic analysis of text and does not contain any form of market feedback.

- Sentiment probabilities, a set of variables which shows the probability of assigning each of the possible sentiment indicators to the news item, with the indicator then assigned to the variable with the highest probability. Intuitively, a news item with a positive news probability of 0.8 can be seen as more positive than one with a probability of 0.2 .

- Relevance, a continuous variable on the $[0,1]$ interval indicating how prominently the company was mentioned in the news article. A relevance score of 1 generally indicates that the company was mentioned directly in the headline.

\footnotetext{
${ }^{2}$ Securities Industry Research Centre of Asia-Pacific (SIRCA) provides data access to this algorithmic textreading tool. TRNA denotes stocks traded on NYSE, NASDAQ and AMEX with .N, .O and .A respectively.
} 
- Novelty, which shows whether the news item is linked to other similar news items or is an item in a sequence of updated news items. In order to ensure that analysis focuses on the arrival of new information only, items with a Linked Count greater than 0 or a Sequence Number greater than 1 are excluded from the sample.

An example of a positive news event would be the message relating to Apple Corp. (AAPL) broadcast at $18: 15: 25$ on $10^{\text {th }}$ January 2006 - "Apple introduces iMac powered by Intel microchip". A negative sentiment score was attached to the broadcast text for General Motors (GM) "Union ends GM Canada blockade, vows to fight on" on $16^{\text {th }}$ June 2008 at 12:48:12. GroßKlußmann and Hautsch (2011) and Smales (2014a) observe that only news categorized as highly relevant has a significant impact on market prices, hence news that is not classified as highly relevant is removed from the sample ${ }^{3}$. The sentiment of news items which arrive during each trading day are aggregated into a daily sentiment measure. In a similar vein to Dzielinski (2011), the sentiment of each news item is multiplied with its probability to compute a weighted average of the prevailing sentiment for that day (Eq.1).

$$
\text { News_Sent }=\frac{\sum 1 \cdot \text { prob }_{\text {positive }}+\sum(-1) \cdot \text { prob }_{\text {negative }}}{100}
$$

This procedure is repeated for each trading day to obtain a complete history of news days and their respective sentiment classification for each stock, and when aggregating at an industry level the news sentiment measures are value-weighted. To ensure that news sentiment is related to returns on a given day, news which occurs after the close of the market, or on days when the market are closed, is aggregated with the news released on the next trading day.

Table 1 Panel A displays summary data for the news sentiment measure for the whole sample, and for each of the 12 industries identified in section 3.2. On average there are 2,160 news items per trading day, with the Business_Equipment industry having the highest number of news items per trading day (316.7) and Utilities having the fewest ((17.9). The frequency of positive news days greatly outnumbers that for negative news days, and average news sentiment on each trading day is 3.03; Manufacturing has the highest average sentiment of 0.27 while Utilities has the lowest (0.02). In all cases the standard deviation of news sentiment is far greater than the mean measure of news sentiment indicating high variation in the measure.

\footnotetext{
${ }^{3}$ The original sample of 6,382,301 news releases is reduced to 3,810,335 highly relevant news items.
} 
$<$ Insert Table 1>

\subsection{Stock Market Returns and Fama-French Factors}

Daily stock market returns are calculated for all CRSP firms incorporated in the U.S. and listed on the NYSE, NASDAQ or AMEX with a CRSP code of 10 or 11 at the start of month $t$. Each stock is assigned to one of 12 industry portfolios on the basis of the four-digit SIC code at that time; Consumer Non-Durables, Consumer Durables, Manufacturing, Energy, Chemicals, Business Equipment, Telecoms, Utilities, Retail, Health, Finance and Other. In addition to data on stock market returns, Fama-French Factors for size (SMB), value (HML) and momentum (MOM) are also obtained from Kenneth French's website ${ }^{4}$.

Summary statistics for stock returns are reported in Table 1 Panel B. The average daily return is $0.027 \%$ for the whole sample, while the Energy industry has the highest average daily return $(0.081 \%)$ and Finance the lowest daily return $(0.005 \%)$; the standard deviation of daily returns is of a much higher magnitude than the mean daily return in all cases. Whilst skewness is not a significant issue, with Utilities (0.627) having the highest level, there is evidence of the high levels of kurtosis typical of stock market returns.

\subsection{CBOE Implied Volatility Index (VIX)}

VIX is an index estimating the level of implied volatility by averaging the weighted prices of SPX puts and calls over a wide range of strike prices ${ }^{5}$, and represents expected market volatility over the next 30 calendar days. The VIX is quoted in percentage points and translate, roughly, to the expected movement in the S\&P 500 Index over the next 30-day period, which is then annualized. For example, if the VIX is 20, this represents an expected annualized change of $20 \%$ over the next 30 days; thus one can infer that the index options markets expect the S\&P 500 to move up or down $5.77 \%(20 \% / \sqrt{ } 12)$ over the next 30 -day period.

The S\&P 500 Index option market is the most active index option market in the US, and is seemingly dominated by portfolio insurers who routinely buy out of the money and at the money index puts for insurance purposes. CBOE reports that total volume of puts was $62 \%$ greater than that of calls in $2010(108.5 \mathrm{~m} \mathrm{v} 66.8 \mathrm{~m})$, hence it is likely that it is put buyers who help to drive changes in implied volatility (VIX) and provides the index with the colloquial name of the "fear

\footnotetext{
${ }^{4}$ http://mba.tuck.dartmouth.edu/pages/faculty/ken.french

${ }^{5}$ For a full explanation of the methodology see http://www.cboe.com/micro/vix/vixwhite.pdf
} 
gauge"; it is the use of VIX as a measure of investor "fear" or sentiment, as explained by Whaley (2000) that is of prime interest. Utilising VIX as a measure of market conditions, rather than the business cycle used in previous work, allows for a more general understanding of how market conditions and investor sentiment might impact the response to news. This is particularly important given the sample period of data available as only one official recession is identified by the National Bureau of Economic Research, yet there are at least two notable periods of extreme investor fear (identified by spikes in VIX) during the global financial crisis of 2008-2009 and the subsequent sovereign debt crisis of 2010.

\section{News sentiment and stock market returns}

\subsection{Identifying a time-varying news sentiment - return relationship}

As a first pass in understanding the relationship between news sentiment and stock market returns I consider the explanatory power of news items on the returns of the 30 stocks contained in the Dow Jones Industrial Average ${ }^{6}$ (DJIA); the 30 stocks are among the largest and most actively traded U.S. stocks and this ensures that investors will be keenly following related news releases. News sentiment and returns are placed within the context of the Fama-French factor asset pricing models, and regressions of the following form are specified:

$$
R_{i, t}-R_{f, t}=a_{i, t}+b_{i, t}\left[R_{M, t}-R_{f, t}\right]+s_{i, t} S M B+h_{i, t} H M L+m_{i, t} M O M+n_{i, t} N e w s_{-} S e n t+e_{i}
$$

Where $R_{f}$ is the risk-free rate of return, $R_{M}-R_{F}$ is the market risk premium, $S M B$ is a risk factor for the difference between a portfolio of small stocks and a portfolio of big stocks, and $H M L$ is the difference between the returns on a portfolio of high book-to-market (value) stocks and a portfolio of low book-to-market (growth) stocks. In addition, $M O M$ is the average return on two high prior return portfolios minus the average return on two low prior return portfolios. Finally, News_Sent is the measure of aggregate news sentiment for the stocks in the index (DJIA).

\section{$<$ Insert Table 2>}

Table 2 reports the results for several specifications of Eq. (2), with Newey-West standard errors. The first column of Panel A shows a highly significant positive relationship between news sentiment and market returns; a positive coefficient would be expected as positive (negative) news should result in higher (lower) returns. When the Fama-French factors are added, news sentiment retains a significant and positive relationship with DJIA returns but the coefficient is

\footnotetext{
${ }^{6}$ Note that value-weighted average index returns are computed and so the returns will not match those of the actual DJIA which is price-weighted.
} 
much smaller; indicating that a $1 \%$ increase in news sentiment is associated with in an additional $0.162 \%$ increase in returns. The beta coefficient for the market risk premium is close to 1 and highly significant, as would be expected by CAPM theory; Momentum is the only insignificant factor.

Panel B disaggregates news into negative and positive components in order to consider the possibility of asymmetric news effects. The first column reports evidence that is consistent with the asymmetric news effect identified in the literature, such that negative news has a highly significant and negative impact on DJIA returns, while positive news has a positive but insignificant impact; the magnitude of the coefficient for negative news is also much larger. However, once the additional Fama-French factors are included the evidence is reversed, in this case positive news is highly significant while negative news has a coefficient of smaller magnitude and is insignificant. This is the first suggestion that the effect of negative news may be systemic in nature, and thus the relationship between news and returns is also related to systemic risk.

$<$ Insert Fig. I $>$

Of additional interest is understanding how the news sentiment - market return relationship evolves over time. This temporal variation is explored using rolling regressions, of the form given in Eq.(2), estimated using 250-day (approximately 1-year of trading days), and depicted in Figure I-Panel A shows the coefficients for beta (market risk premium) and news sentiment coefficients; clearly both are time-varying, for beta this is consistent with Fama and French (1997) but for the news sentiment measure this is a newly identified phenomenon. Indeed, visually there appears to be a close relationship between beta and news sentiment, which Figure II suggests is almost linear in nature. This relationship diverges from mid-2007 to early2009 (coinciding with the global financial crisis) and again in 2010 (coinciding with the onset of the sovereign debt crisis in Europe). Similarly, Panel B depicts negative and positive news coefficients together with beta. Prior to the global financial crisis a close relationship is observed for all three coefficients. However, from September 2008 (coinciding with Lehman Brother failing) the positive news coefficient diverges and becomes greater in magnitude while the negative news coefficient appears to track beta. One explanation for the increased importance of positive news during this time could be the plethora of negative news prevailing in the market (Panel C shows news sentiment is very negative during this period). Taken together, the evidence in Figure I is suggestive of the time-varying nature of the news-return relationship being systemic 
in nature, and diverging when negative news dominates the news-wire and investors may potentially be in "fear".

$<$ Insert Fig. II $>$

\subsection{Does the news sentiment-return relationship differ by industry?}

Fama and French (1997) note that the beta coefficient differs across industries, and so the relationship between beta and news coefficients identified in Section 4.1 suggests that the news return relationship should also differ; this section seeks to determine whether this is indeed the case. Figure III shows how news sentiment varies over time for each of the 12 industries. There are two noticeable declines in news sentiment for the majority of industries - the first occurring in the aftermath of the failure of two funds at Bear Sterns in mid-2007 which precipitated the sub-prime crisis, and the second, much larger decline following the bankruptcy of Lehman Brothers in September 2008. The VIX is also presented as an indication for investor "fear" over the sample period; note that VIX rises as news sentiment is falling. Despite this heightened level of investor concerns, and the general unstable economic environment during this period only the energy industry has a news sentiment moving-average that falls below zero - likely a result of crude oil prices falling $70 \%$ during this period.

\section{$<$ Insert Fig. III >}

The nature of the industry specific news sentiment - return relationship is investigated using regression specifications of the form shown in Eq.(2) with industry specific returns and news sentiment measures substituting for those of DJIA constituents. The first three columns of Table 3 report the coefficients for the baseline regression ${ }^{7}$ with an aggregated news coefficient, and the last three columns report results for the news coefficient when disaggregated into negative and positive news. The coefficient for the market risk premium (i.e. beta) is positive and significant for all industry portfolios, and the news coefficient also tends to be positive and significant with Chemicals, Energy, and Other proving exceptions to this rule. It is possible that Other contains too broad a range of companies to form any meaningful relationship with aggregated news measures, while Chemicals and Energy returns may be more related to other, market-wide, news that for Energy is reflected in this industry having the highest beta. For the 9 industry portfolios that do bear the expected relationship the news sentiment coefficient tends to increase as beta increases; for instance, Consumer Durables has the highest beta and highest news

\footnotetext{
${ }^{7}$ For the sake of brevity only the coefficients for beta and the news coefficient are reported here, the coefficients for the other Fama-French factors are omitted.
} 
coefficient, while Health has the lowest beta and the second lowest news coefficient. This is consistent with the idea that the premium to induce risk-averse investors to bear risk is related to non-diversifiable (firm-specific or industry-specific) risk. For disaggregated news, the previously observed asymmetric relationship is generally observed with negative news having a greater influence than positive news; however this relationship is reversed for the two industries (Consumer Durables and Manufacturing) with the highest aggregated news coefficient.

\section{$<$ Insert Table 3>}

\subsection{The time-varying nature of industry specific news-return relationships}

Having identified that the news sentiment - return relationship is industry specific, it is important to investigate the time-varying nature of this relationship and provide suggestions as to what might influence changes in this relationship.

\section{$<$ Insert Table 4>}

A starting point in understanding the variation in the relationship is to perform rolling regressions, of the form shown in Eq.(2), and calculate the standard deviation of the estimated news sentiment coefficients; Table 4 reports the results for both beta and news coefficients using a rolling 250-day sample period. Standard deviations for the news coefficients are generally much larger (almost $3 \mathrm{x}$ on average) than those calculated for beta, and also tend to be larger than the news sentiment coefficient estimated for the whole sample period indicating a high degree of instability in that coefficient. Apparently industries with higher (lower) variation in beta also tend to have a higher (lower) variation in the news sentiment coefficient.

$<$ Insert Fig. IV $>$

The evolution of estimated news sentiment and beta coefficients over time ${ }^{8}$ is depicted in Figure IV. The time-varying nature of the coefficients is clearly evident as is the relationship between beta and news coefficients. The relationship between news sentiment and investor fear ${ }^{9}$ (Panel A), and between beta and fear (Panel B) is more complicated. There is a clear link between beta and VIX, particularly as VIX rises sharply during the sovereign debt crisis of 2010 and to a lesser extent as VIX spikes during the global financial of 2008-2009; this makes sense if beta reflects systemic risk and VIX is reflective of investor fear resulting from perceived changes in this risk. Indeed, this finding is consistent with evidence from Choudhry (2005a, 2005b) that beta is affected by crisis and increased levels of concern among investors.

\footnotetext{
${ }^{8}$ Only 4 industries are plotted along with VIX in order to provide graphical clarity.

${ }^{9}$ Proxied by the CBOE Volatility Index (VIX)
} 
For most industries there is no relationship between VIX and news sentiment for the first part of the sample, Chemicals and Energy are exceptions as the news sentiment coefficient closely tracks VIX. During periods when investors are fearful (depicted by high levels of VIX) then the news sentiment measure of a greater number of industries follows changes in VIX. As VIX subsides once more this relationship again breaks down, although not for Chemicals and Energy.

To be clear, industries identified as having a significant industry-specific news sentiment return relationship have an estimated news coefficient that does not follow VIX apart from during times of crisis (high VIX), while those industries whose returns do not appear to respond to industry specific news (Chemicals and Energy) follow have coefficients closely correlated with VIX throughout the sample period. Since VIX is an indicator of market wide sentiment it should also incorporate market wide news. Therefore, it is likely that Chemicals and Energy are responding to market wide news rather than industry-specific news and thus the industry-specific news is subsumed by the measure of beta in the regression analysis, giving an insignificant news coefficient; this result may have implications for the other industries.

During periods when the industry-specific news coefficient starts to track investor fear, then industry-specific news may no longer be important, the estimated coefficients will be insignificant and systemic news would be much more important. This supposition is tested by repeating the earlier regressions with the sample split into two; periods when VIX is high (top quintile) and all other periods. Table 5 reports the aggregated and disaggregated news coefficients for each industry. In the first sample, when investor fear is high none of the aggregated news coefficients are significant; although in general the magnitude of the coefficients is higher than in the overall sample the increase in the standard error is even greater. Considering news disaggregated into negative and positive components, unlike in the overall sample and the extant literature, there is no clear pattern of the sign of coefficients, and only Energy and Utility have significant negative news coefficients. Taken together, the results suggest that, during periods of investor "fear", industry returns are dominated by market-wide news that drives this fear rather than industry-specific news. This is inconsistent with the extant literature on time-varying response to macroeconomic news, or news sentiment (Garcia, 2013) since the focus there is on market-wide news rather than firm- or industry-specific news.

When investor fear is lower (last three columns) then the reported coefficients are as one would expect; aggregated news coefficients are positive and significant (even for Chemicals), 
negative (positive) news coefficients are negative (positive). One important factor to note is that while the coefficients for negative news are generally of a greater magnitude than those reported for positive news, only the negative coefficient for Durables is significant, whereas the positive coefficient is significant for all but Energy, this is not entirely consistent with the asymmetric news effect identified elsewhere in the literature.

\section{$<$ Insert Table 5>}

To summarize, the influence of news sentiment on industry returns is time-variant and related to the market risk premium coefficient; industries with higher (lower) variation in beta also tend to have a higher (lower) variation in the news sentiment coefficient. Two types of industry-specific news sentiment - portfolio return relationships are identified. First, returns in the Chemicals and Energy industries respond mainly to systemic factors (such as energy prices) and track changes in investor sentiment (VIX) over time; the news sentiment coefficient is insignificant. Second, the other identified industries have a significant news coefficient for the overall sample but this is not the case during high levels of investor fear when systemic news / sentiment dominate.

\section{5. $\quad$ Robustness Tests}

\subsection{General portfolios}

The empirical analysis in Section 4 concentrates on the DJIA (with large and heavily traded constituents) and industry specific portfolios; it is possible that alternative stocks or portfolio specifications may not share the same news sentiment - return relationship. Table 6 reports results for a broader range of portfolios formed on size (market capitalisation), book-to-market and momentum, and regressed as per Eq.(2), with the results supportive of the prior analysis. However the portfolios are formed, the aggregated news coefficients are positive and significant (with the smallest firms acting as the single exception) and there appears to be some evidence of an asymmetric response to news; the coefficients for negative news are of a much greater magnitude than for positive news sentiment (over 3 times greater on average) but they are generally insignificant owing to the large standard errors.

$<$ Insert Table 6>

Panel A shows that the news sentiment coefficient increases with the size of the company, a result consistent with more investors following the news for larger companies and responding to that news; the very smallest stocks do not have a significant relationship with news sentiment suggesting. Panel B shows that growth stocks have the highest response to news, particularly 
negative news, and this response generally declines as the book-to-market falls (this is not true for the stocks with the highest book-to-market ratio). When sorted by size and book-to-market (Panel C) it appears that news impact decreases in-line with the book-to-market ratio, for big companies the value stocks have the largest news coefficient which is consistent with the Consumer Durables industry having the largest news coefficient. Performing the analysis on a more broadly defined set of portfolios confirms the results in Section 4.

\subsection{Specification of news sentiment measure and portfolios}

The analysis reported in this paper utilises value-weighted industry-specific news sentiment measures and industry portfolios. The analysis has also being conducted with equal-weighted portfolios and equivalent news sentiment measures, and the results are qualitatively similar. Indeed results are also robust to using value-weighted industry portfolios with equal-weighted news sentiment measures and vice-versa.

The news sentiment measure defined in Eq.(1) is an aggregated measure of the weighted average of news sentiment divided by 100. It is possible to scale this measure in a number of ways including dividing by the total number of news items for the company, the size of the company, or by ignoring the probability of news being correctly classified as negative or positive and taking a simple sum of news sentiment; again the results are qualitatively similar.

The event window used for applicable news runs from the close of one trading day to the close of the next, such that investors are able to respond to that news on the given day. It is possible to exclude news events that occur outside of market hours, or extend the period over which news is aggregated. Excluding overnight news has little discernible impact on the results reported, however as the aggregation period becomes longer the news sentiment coefficients quickly become insignificant (particularly after 3 days) as a result of both declining magnitude of coefficients and increasing standard error.

\section{Conclusion}

Financial decisions rely on investors having a reasonable understanding as to the prospective return on investment under varying market conditions, and in light of numerous news events. I find clear empirical evidence that the influence of news on stock market returns varies over time, and this variation is related to the market risk premium.

Consistent with Durand et al. (2011), it is apparent that investor fear, encapsulated by VIX, affects stock market returns by impacting risk factors and the influence of news sentiment. When 
investor fear is high, then industry-specific news does not play a significant role in determining returns which are instead driven by systemic factors; this is consistent with Garcia (2013) such that predictability of stock returns using general financial news is concentrated in recessions. At other times there is a clear relationship between industry-specific news sentiment and returns for the majority of industries. Such results are important for investors wishing to understand how their portfolios will respond to news events. In particular, algorithmic traders that use news sentiment measures for trading decisions may need to exercise extra caution during periods of market stress and investor fear. Possible extensions to this topic could involve the application to international stocks, other asset classes, and also consideration of high-frequency data.

\section{References}

Antweiler, W., and M.Z. Frank, 2004, Is all that talk just noise? The information content of internet stock message boards, Journal of Finance, 59, 1259-1294

Basishta, A., and A. Kurov, 2008, Macroeconomic cycles and the stock market's reaction to monetary policy, Journal of Banking and Finance, 32, 2606-2616

Bollerslev, T., R.F. Engle, and J.M. Wooldridge, 1998, A capital asset pricing model with timevarying covariances, Journal of Political Economy, 96, 116-131

Bos, T., and P. Newbold, 1984, An empirical investigation of the possibility of stochastic systematic risk in the market model, Journal of Business, 57, 35-41

Boyd, J.H., J. Hu, and R. Jagannathan, 2005, The stock market's reaction to unemployment news: Why bad news is usually good for stocks, Journal of Finance, 60, 649-672

Brooks, R.D., R.W. Faff and J.H.H. Lee, 1992, The form of time variation of systematic risk: Some Australian evidence, Applied Financial Economics, 2, 191-198

Brooks, R.D., R.W. Faff and J.H.H. Lee, 1994, Beta stability and portfolio formation, Pacific-Basin Finance Journal, 2, 463-479

Brooks, R.D., R.W. Faff, and M.D. McKenzie, 1998, Time-varying beta risk of Australian industry portfolios: A comparison of modelling techniques, Australian Journal of Management, 23, 1-22

Carhart, M. M., 1997, On persistence in mutual fund performance, Journal of Finance, 52, 57-82

Choudhry, T., 2005a, Time-varying beta and the Asian financial crisis: Evidence from Malaysian and Taiwanese firms, Pacific-Basin Finance Journal, 13, 93-118

Choudhry, T., 2005b, September 11 and time-varying beta of United States companies, Applied Finance Economics, 15, 1227-1242 
Choudhry, T., L. Lu, and K. Peng, 2010, Time-varying beta and the Asian financial crisis: Evidence from the Asian industrial sectors, Japan and the World Economy, 22, 228-234

Durand, R.B., D. Lim, and J.K. Zumwalt, 2011, Fear and the Fama-French factors, Financial Management, 40, 409-426

Durand, R.B., D. Lim, and J.W. Yang, 2014, The microstructure of fear: The Fama-French factors and the global financial crisis of 2007 and 2008, Global Finance Journal, In Press

Dzielinski, M., 2011, News sensitivity and the cross-section of stock returns, NCCR Finrisk working paper no. 719

Fabozzi, F.J. and J.C. Francis, 1978, Beta as a random coefficient, Journal of Financial and Quantitative Analysis, 13, 101-105

Fama, E.F., and K.R. French, 1992, The cross-section of expected stock returns, Journal of Finance, 47, 427-465

Fama, E.F., and K.R. French, 1993, Common risk factors in the returns on stocks and bonds, Journal of Financial Economics, 33, 3-56

Fama, E.F., and K.R. French, 1997, Industry costs of equity, Journal of Financial Economics, 43, 153-193

French, K.R., G.W. Schwert, and R. Stambaugh, 1987, Expected stock returns and volatility, Journal of Financial Economics, 19, 3-30

Garcia, D., 2013, Sentiment during recessions, Journal of Finance, 68, 1267-1300

Groß-Klußmann, A., and N. Hautsch, 2011, When machines read the news: Using automated text analytics to quantify high frequency news-implied market reactions, Journal of Empirical Finance, 18, 321-340

Hamilton, J.D., and G. Lin, 1996, Stock market volatility and the business cycle, Journal of Applied Econometrics, 11, 573-593

Kandel, S., and R.F. Stambaugh, 1990, Expectations and volatility of consumption and asset returns, Review of Financial Studies, 3, 207-232

Kim, D., 1993, The extent of non-stationarity of beta, Review of Quantitative Finance and Accounting, 3, 241-254

Knif, J., J. Kolari, and S. Pynnonen, 2008, Stock market reaction to good and bad inflation news, Journal of Financial Research, 31, 141-166

Kurov, A., 2010, Investor sentiment and the stock market's reaction to monetary policy, Journal of Banking and Finance, 34, 139-149 
Leinweber, D., and J. Sisk, 2011, Event driven trading and the 'new news', Journal of Portfolio Management, 38, 110-124

Lintner, J., 1965, The valuation of risk assets and the selection of risky investments in stock portfolios and capital budgets, Review of Economics and Statistics, 47, 13-37

McQueen, G., and V.V. Roley, 1993, Stock prices, news, and business conditions, Review of Financial Studies, 6, 683-707

Mindell, J., 1961, How news affects market trends, Financial Analysts Journal, 1, 31-34

Sharpe, W.F., 1964, Capital asset prices: a theory of market equilibrium under conditions of risk, Journal of Finance, 19, 425-442.

Smales, L.A., 2014a, Non-scheduled news arrival and high-frequency stock market dynamics: Evidence from the Australian stock exchange, Research in International Business and Finance, 32, $122-138$

Smales, L.A., 2014b, News sentiment in the gold futures market, Working Paper

Tetlock, P.C., 2007, Giving content to investor sentiment: The role of media in the stock market, Journal of Finance, 62, 1139-1168

Tetlock, P.C., M. Saar-Tsechansky, and S. Macskassy, 2008, More than words: Quantifying language to measure firms' fundamentals, Journal of Finance, 63, 1437-1467

Whaley, R.E., 2000, The investor fear gauge, Journal of Portfolio Management, 26, 12-17

Zhang, Y., P.E. Swanson, and W. Prombutr, 2012, Measuring effects on stock returns of sentiment indexes created from stock message boards, Journal of Financial Research, 35, 79-114 


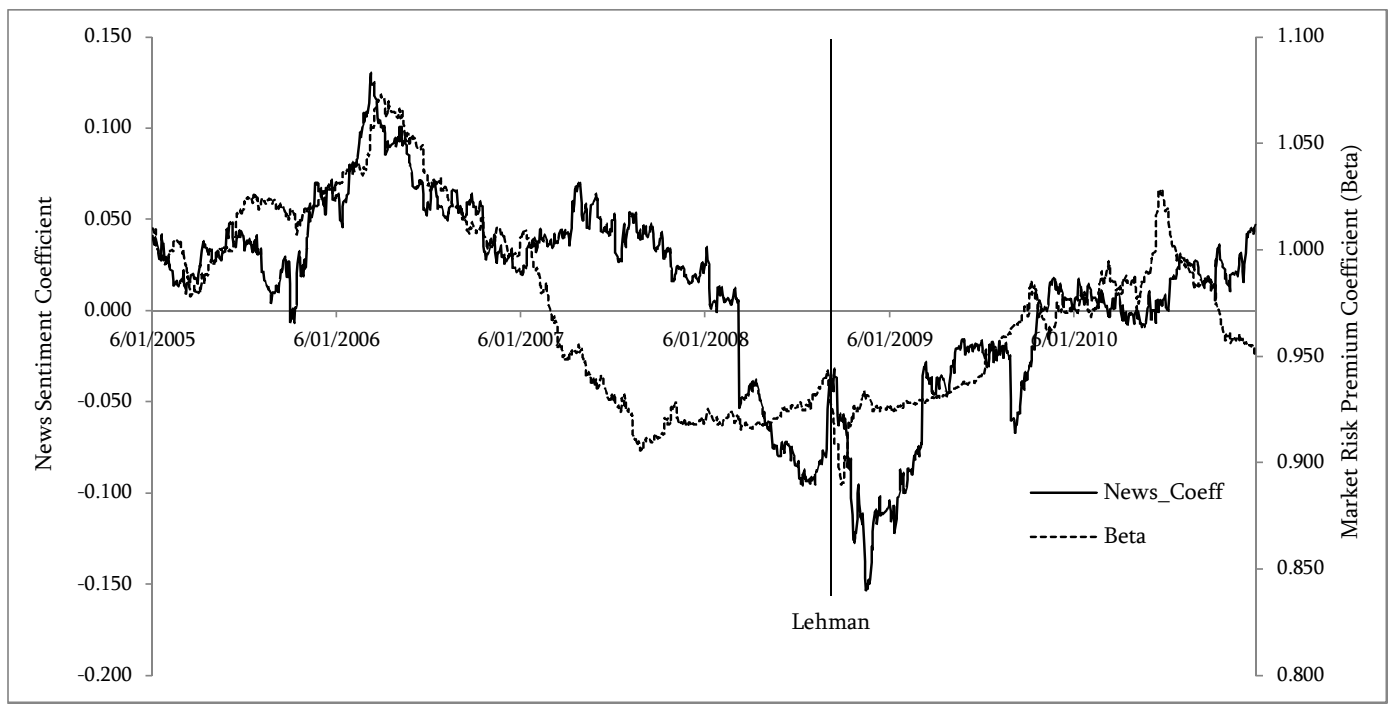

Figure I-Panel A . Evolution of regression coefficients for news sentiment and market risk premium

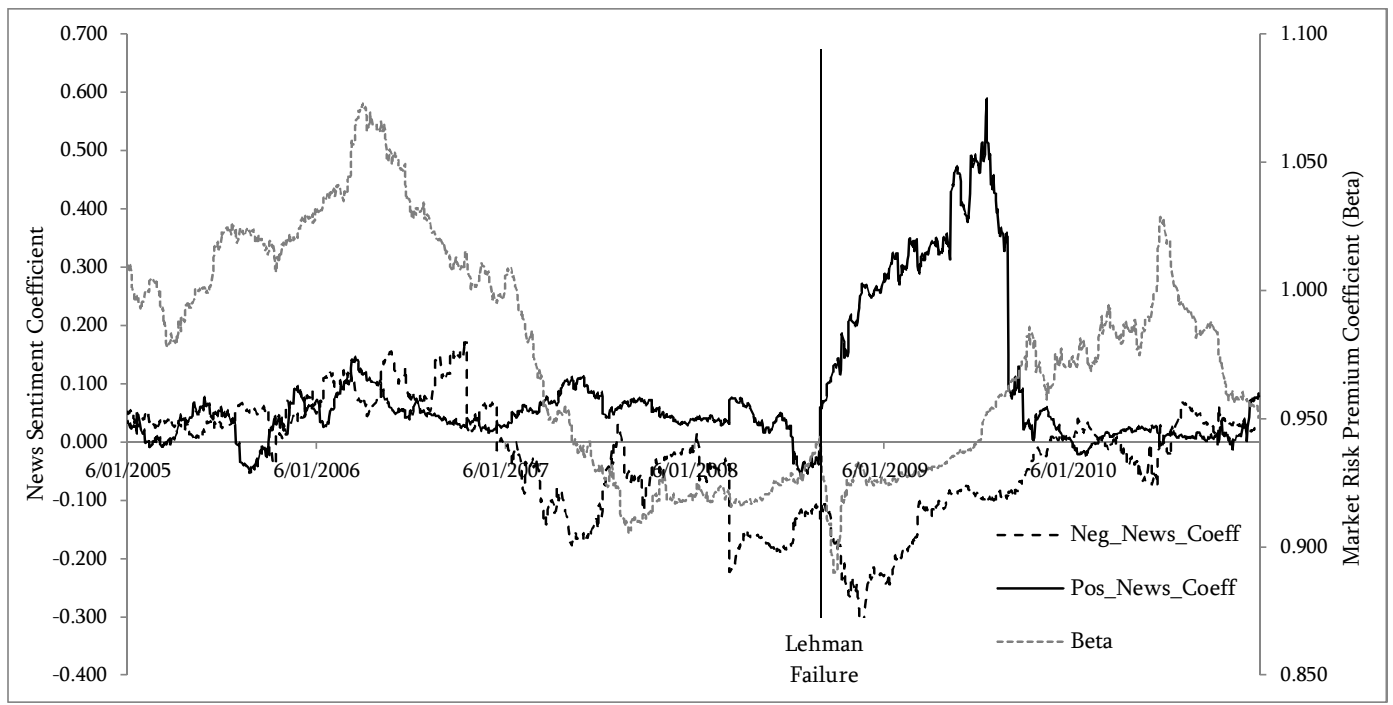

Figure I-Panel B . Evolution of regression coefficients for negative and positive news sentiment

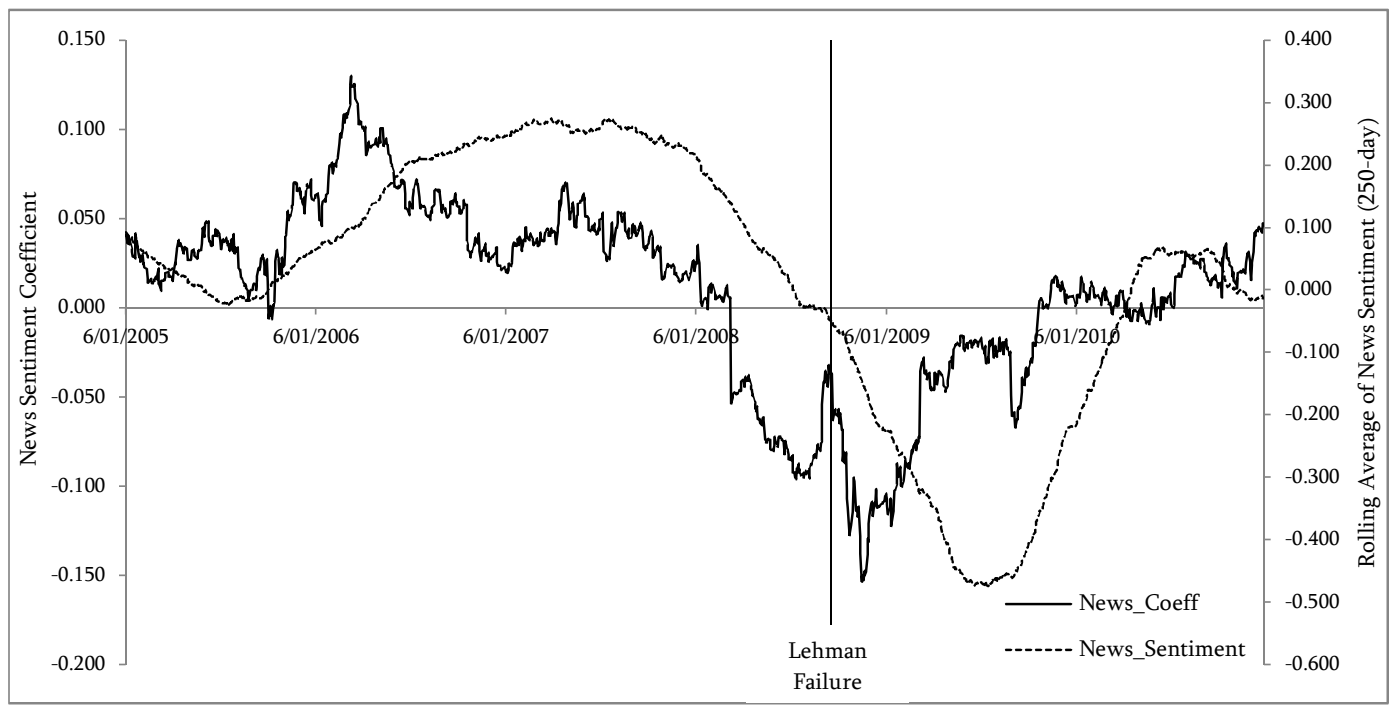

Figure I-Panel C . Evolution of regression coefficient for news sentiment and 250-day moving average of news sentiment measure 


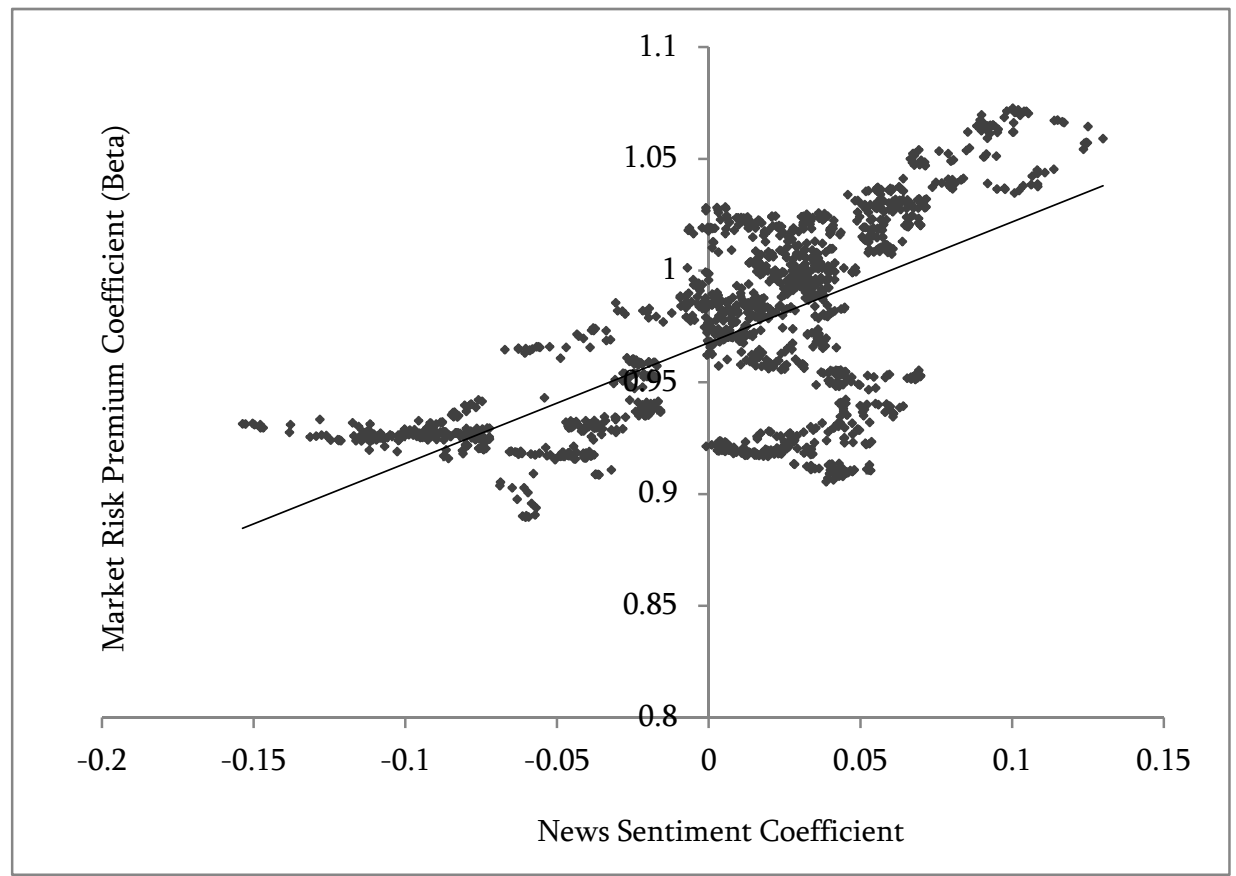

Figure II. Regression coefficients for news sentiment and the market risk premium 


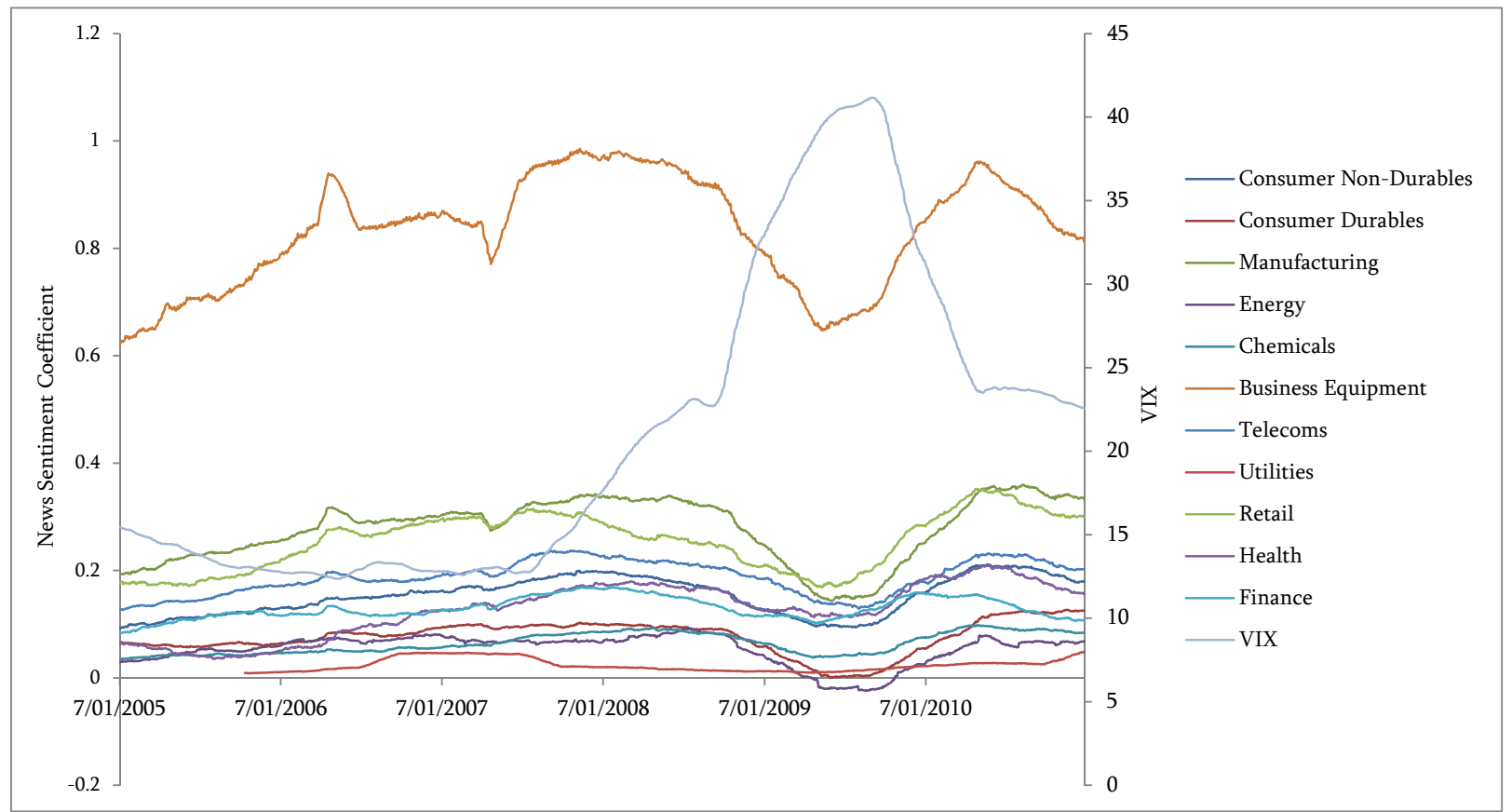

Figure III. 250-day moving-average of industry-specific news sentiment 


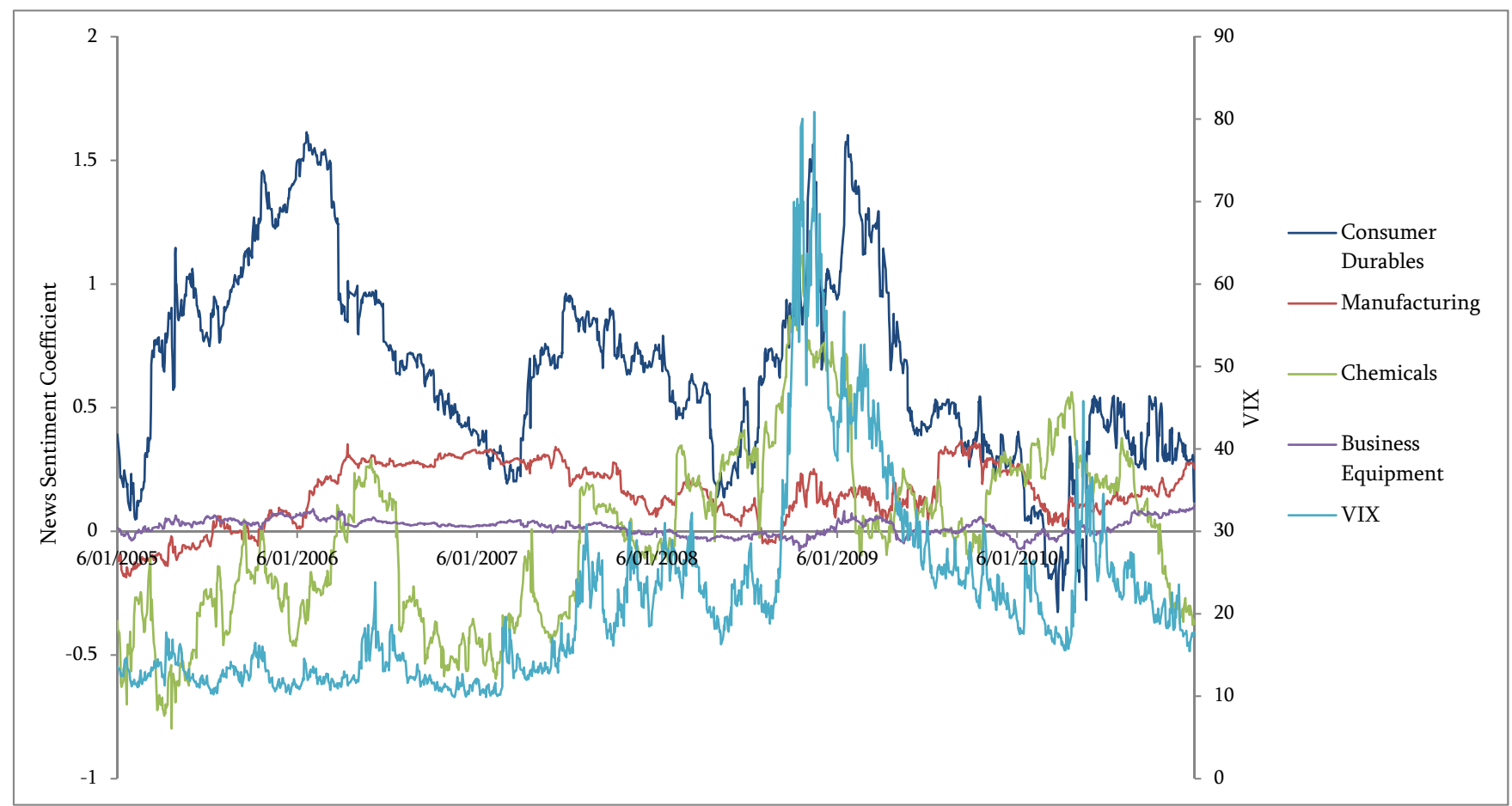

Figure IV - Panel A. Evolution of news sentiment regression coefficient and VIX

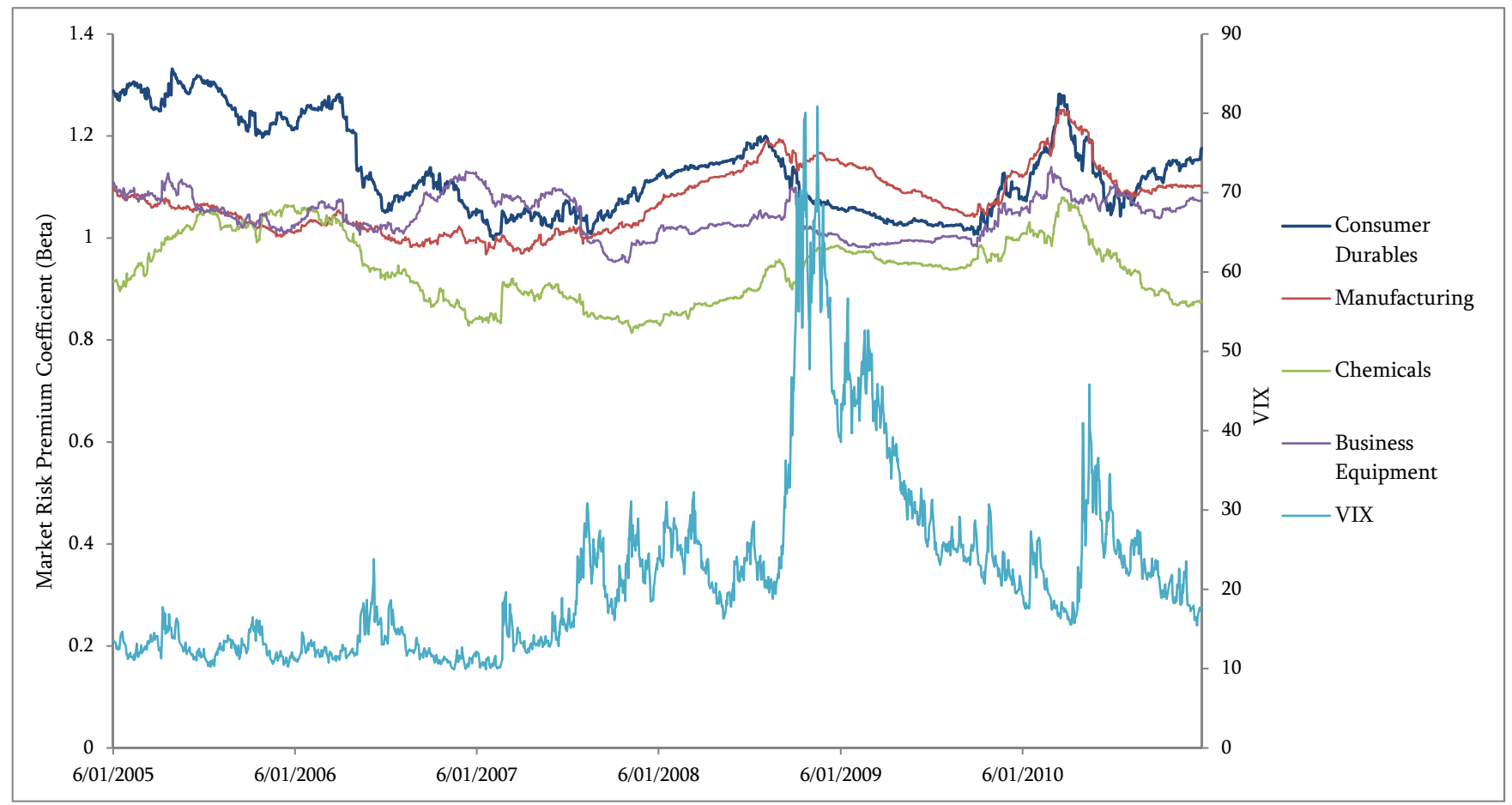

Figure IV - Panel B. Evolution of market risk premium regression coefficient and VIX 
Table

Taptive Statistic

Descriptive statistics for daily intervals are provided for aggregated news sentiment and returns for the industry portfolios and constituent stocks for the Dow Jones Industrial Average (DJIA). Sample period is 02 January 2004 - 31 December 2011

\begin{tabular}{|c|c|c|c|c|c|c|c|c|c|c|c|c|c|c|}
\hline & Whole Sample & $\begin{array}{c}\text { Dow-Jones Industrial } \\
\text { Average Stocks }\end{array}$ & $\begin{array}{c}\text { Consumer Non- } \\
\text { Durables }\end{array}$ & $\begin{array}{c}\text { Consumer } \\
\text { Durables }\end{array}$ & Manufacturing & Energy & Chemicals & $\begin{array}{c}\text { Business } \\
\text { Equipment }\end{array}$ & Telecoms & Utilities & Retail & Health & Finance & Other \\
\hline \multicolumn{15}{|l|}{ Panel A: News Sentiment } \\
\hline $\begin{array}{l}\text { Total No. News Items } \\
\text { Average number of news items per trading day }\end{array}$ & $\begin{array}{c}3810335 \\
2160.1\end{array}$ & $\begin{array}{c}748062 \\
424.1\end{array}$ & $\begin{array}{c}172289 \\
97.7\end{array}$ & 110308 & $\begin{array}{c}278511 \\
157.9\end{array}$ & 159208 & 71013 & 558661 & $\begin{array}{c}158593 \\
89.9\end{array}$ & 31492 & $\begin{array}{c}315160 \\
178.7\end{array}$ & $\begin{array}{c}3116899 \\
176.7\end{array}$ & $\begin{array}{c}1468898 \\
83.3\end{array}$ & $\begin{array}{c}1496503 \\
848.4\end{array}$ \\
\hline & $\begin{array}{c}2160.1 \\
61\end{array}$ & $\begin{array}{l}424.1 \\
764\end{array}$ & $\begin{array}{l}97.7 \\
195\end{array}$ & $\begin{array}{l}62.5 \\
311\end{array}$ & $\begin{array}{c}157.9 \\
114\end{array}$ & $\begin{array}{l}90.3 \\
460\end{array}$ & $\begin{array}{l}40.3 \\
268\end{array}$ & $\begin{array}{c}310.7 \\
33\end{array}$ & $\begin{array}{l}89.9 \\
122\end{array}$ & $\begin{array}{l}17.9 \\
343\end{array}$ & $\begin{array}{c}178.7 \\
115\end{array}$ & 384 & 182 & 184 \\
\hline No. Neutral news days & 0 & 6 & 16 & 13 & 13 & 17 & 34 & 5 & 22 & 60 & 9 & 11 & 16 & 5 \\
\hline No. Positive news days & 1703 & 994 & 1553 & 1440 & 1637 & 1287 & 1462 & 1726 & 1620 & 1361 & 1640 & 1369 & 1566 & 1575 \\
\hline Average news sentiment per trading day & 3.03 & 0.02 & 0.15 & 0.08 & 0.27 & 0.05 & 0.06 & 0.81 & 0.18 & 0.02 & 0.25 & 0.13 & 0.12 & 0.92 \\
\hline Standard deviation of news sentiment & 1.86 & 0.43 & 0.14 & 0.11 & 0.21 & 0.15 & 0.08 & 0.49 & 0.16 & 0.04 & 0.21 & 0.17 & 0.11 & 0.90 \\
\hline Minimum news sentiment & -4.11 & -2.34 & -0.33 & -0.52 & -0.77 & -1.86 & -0.64 & -0.34 & -0.81 & -0.23 & -0.91 & -0.72 & -0.27 & -6.87 \\
\hline Maximum news sentiment & 16.40 & 2.41 & 1.14 & 0.73 & 1.51 & 1.20 & 0.54 & 4.32 & 1.23 & 0.29 & 1.48 & 0.91 & 0.90 & 6.82 \\
\hline \multicolumn{15}{|l|}{ Panel B: Returns } \\
\hline Mean & 0.027 & 0.004 & 0.035 & 0.024 & 0.046 & 0.081 & 0.038 & 0.030 & 0.028 & 0.045 & 0.031 & 0.019 & 0.005 & 0.024 \\
\hline Std. Dev & 1.37 & 1.27 & 1.01 & 1.92 & 1.63 & 2.00 & 1.27 & 1.47 & 1.45 & 1.31 & 1.29 & 1.08 & 2.18 & 1.48 \\
\hline Min & -8.95 & -8.20 & -6.87 & -10.40 & -10.51 & -15.49 & -8.61 & -8.63 & -9.67 & -8.92 & -8.22 & -6.70 & -14.84 & -8.74 \\
\hline Max & 11.35 & 10.51 & 10.28 & 9.73 & 11.41 & 19.33 & 9.86 & 11.89 & 14.51 & 14.43 & 10.99 & 11.09 & 14.66 & 9.92 \\
\hline Skewness & -0.05 & 0.03 & 0.27 & -0.24 & -0.15 & 0.03 & -0.11 & 0.15 & 0.60 & 0.63 & 0.20 & 0.18 & 0.27 & -0.21 \\
\hline Kurtosis & 13.13 & 14.15 & 16.88 & 7.90 & 9.92 & 14.92 & 11.88 & 9.85 & 18.35 & 19.70 & 10.10 & 14.65 & 13.81 & 9.39 \\
\hline Beta & & 0.90 & 0.66 & 1.27 & 1.13 & 1.17 & 0.85 & 1.00 & 0.97 & 0.78 & 0.85 & 0.67 & 1.42 & 1.03 \\
\hline
\end{tabular}


Table 2

News sentiment and returns on constituents of DJIA

This table presents coefficients for the regression specified in Eq. (2) where returns on the consituent stocks of the Dow Jones Industrial Average (DJIA) are regressed on the four factor Fama French model and aggregated news sentiment measures. Newey West standard errors are reported in brackets. Sample Period: 02 Jan 2004 - 31 Dec 2010.

\begin{tabular}{|c|c|c|c|c|c|c|c|c|c|c|c|c|c|c|c|c|c|}
\hline \multirow{2}{*}{\multicolumn{9}{|c|}{$\begin{array}{l}\text { Panel } A: \text { Aggregated News } \\
\text { Dependent Variable: Return on DJIA Stocks }\end{array}$}} & \multicolumn{9}{|c|}{ Panel $B:$ Negative and Positive News Components } \\
\hline & & & & & & & & & \multicolumn{9}{|c|}{ Dependent Variable: Return on DJIA Stocks } \\
\hline & $(1)$ & 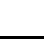 & $(2)$ & . & $(3)$ & \multicolumn{3}{|c|}{$(4)$} & & $(1)$ & & $(2)$ & & (3) & \multicolumn{3}{|c|}{$(4)$} \\
\hline \multirow[t]{2}{*}{ Alpha } & 0.011 & & 0.022 & *** & 0.019 & *** & 0.019 & *** & Alpha & 0.028 & & 0.032 & *** & 0.034 & *** & 0.034 & ** \\
\hline & $(0.027)$ & & $(0.006)$ & & $(0.006)$ & & $(0.006)$ & & & $(0.043)$ & & $(0.009)$ & & $(0.009)$ & & $(0.009)$ & \\
\hline \multirow[t]{2}{*}{$R m-R f$} & & & 0.902 & $* * *$ & 0.928 & $* * *$ & 0.929 & *** & $R m-R f$ & & & 0.903 & $* * *$ & 0.929 & $* * *$ & 0.929 & *** \\
\hline & & & $(0.009)$ & & $(0.007)$ & & $(0.008)$ & & & & & $(0.010)$ & & $(0.007)$ & & $(0.008)$ & \\
\hline \multirow[t]{2}{*}{$S M B$} & & & & & -0.188 & $* * *$ & -0.188 & $* * *$ & $S M B$ & & & & & -0.189 & $* * *$ & -0.189 & *** \\
\hline & & & & & $(0.018)$ & & $(0.018)$ & & & & & & & $(0.018)$ & & $(0.018)$ & \\
\hline \multirow[t]{2}{*}{$H M L$} & & & & & -0.077 & $* * *$ & -0.075 & $* * *$ & $H M L$ & & & & & -0.078 & $* * *$ & -0.076 & *** \\
\hline & & & & & $(0.021)$ & & $(0.018)$ & & & & & & & $(0.021)$ & & $(0.018)$ & \\
\hline \multirow[t]{2}{*}{$M O M$} & & & & & & & 0.002 & & $M O M$ & & & & & & & 0.003 & \\
\hline & & & & & & & $(0.011)$ & & & & & & & & & $(0.011)$ & \\
\hline \multirow[t]{4}{*}{ News } & 0.269 & $* * *$ & 0.028 & $* *$ & 0.017 & $* *$ & 0.016 & $* *$ & Negative News & -0.332 & $* * *$ & -0.001 & & -0.024 & & -0.024 & \\
\hline & $(0.095)$ & & $(0.012)$ & & $(0.007)$ & & $(0.007)$ & & & $(0.124)$ & & $(0.035)$ & & $(0.033)$ & & $(0.033)$ & \\
\hline & & & & & & & & & Positive News & 0.131 & & 0.064 & ** & 0.067 & $* * *$ & 0.067 & *** \\
\hline & & & & & & & & & & (0.099) & & $(0.026)$ & & $(0.023)$ & & $(0.023)$ & \\
\hline $\mathrm{N}$ & 1742 & & 1742 & & 1742 & & 1742 & & $\mathrm{~N}$ & 1742 & & 1742 & & 1742 & & 1742 & \\
\hline $\mathrm{R}^{2}$ & 0.0086 & & 0.957 & & 0.965 & & 0.965 & & $\mathrm{R}^{2}$ & 0.0092 & & 0.957 & & 0.965 & & 0.965 & \\
\hline
\end{tabular}

${ }^{* * *},{ }^{* *}$, and ${ }^{*}$ denote significance at the $1 \%, 5 \%$ and $10 \%$ levels respectively. 


\section{Table 3}

News sentiment and industry returns

This table presents coefficients for the regression specified in Eq. (2) where returns on the specified industries are regressed on the four factor Fama French model and aggregated industry-specific news sentiment measures. Only coefficients for the market risk premium (beta) and news sentiment measures are reported. Newey West standard errors are reported in brackets. Sample Period: 02 Jan 2004 31 Dec 2010.

\begin{tabular}{|c|c|c|c|c|c|c|c|c|c|c|}
\hline Industry & $\mathrm{Rm}-\mathrm{Rf}$ & & News & & $\mathrm{R}^{2}$ & Negative News & & Positive News & & $\mathrm{R}^{2}$ \\
\hline Consumer Non-Durables & $\begin{array}{c}0.772 \\
(0.018)\end{array}$ & *** & $\begin{array}{c}0.046 \\
(0.017)\end{array}$ & *** & 0.826 & $\begin{array}{l}-0.331 \\
(0.159)\end{array}$ & ${ }^{* *}$ & $\begin{array}{c}0.020 \\
(0.076)\end{array}$ & & 0.827 \\
\hline Consumer Durables & $\begin{array}{c}1.235 \\
(0.021)\end{array}$ & $* * *$ & $\begin{array}{c}0.614 \\
(0.214)\end{array}$ & *** & 0.865 & $\begin{array}{l}-0.285 \\
(0.118)\end{array}$ & $* *$ & $\begin{array}{c}0.726 \\
(0.198)\end{array}$ & *** & 0.865 \\
\hline Manufacturing & $\begin{array}{c}1.143 \\
(0.012)\end{array}$ & $* * *$ & $\begin{array}{c}0.140 \\
(0.052)\end{array}$ & *** & 0.924 & $\begin{array}{l}-0.095 \\
(0.030)\end{array}$ & *** & $\begin{array}{c}0.143 \\
(0.057)\end{array}$ & $* *$ & 0.923 \\
\hline Energy & $\begin{array}{c}1.330 \\
(0.066)\end{array}$ & $* * *$ & $\begin{array}{l}-0.072 \\
(0.223)\end{array}$ & & 0.710 & $\begin{array}{l}-0.378 \\
(0.163)\end{array}$ & $* *$ & $\begin{array}{c}0.207 \\
(0.257)\end{array}$ & & 0.711 \\
\hline Chemicals & $\begin{array}{c}0.917 \\
(0.015)\end{array}$ & $* * *$ & $\begin{array}{l}-0.005 \\
(0.051)\end{array}$ & & 0.855 & $\begin{array}{l}-0.183 \\
(0.198)\end{array}$ & & $\begin{array}{c}0.039 \\
(0.037)\end{array}$ & & 0.855 \\
\hline Business Equipment & $\begin{array}{c}1.073 \\
(0.019)\end{array}$ & $* * *$ & $\begin{array}{c}0.127 \\
(0.037)\end{array}$ & *** & 0.896 & $\begin{array}{l}-0.709 \\
(0.330)\end{array}$ & $* *$ & $\begin{array}{c}0.032 \\
(0.019)\end{array}$ & $* *$ & 0.896 \\
\hline Telecoms & $\begin{array}{c}0.968 \\
(0.032)\end{array}$ & $* * *$ & $\begin{array}{c}0.078 \\
(0.038)\end{array}$ & $* *$ & 0.851 & $\begin{array}{l}-0.098 \\
(0.048)\end{array}$ & $* *$ & $\begin{array}{c}0.076 \\
(0.037)\end{array}$ & $* *$ & 0.852 \\
\hline Utilities & $\begin{array}{c}0.886 \\
(0.045)\end{array}$ & $* * *$ & $\begin{array}{c}0.043 \\
(0.018)\end{array}$ & ** & 0.730 & $\begin{array}{l}-0.064 \\
(0.023)\end{array}$ & *** & $\begin{array}{c}0.052 \\
(0.356)\end{array}$ & & 0.731 \\
\hline Retail & $\begin{array}{c}0.858 \\
(0.021)\end{array}$ & $* * *$ & $\begin{array}{c}0.018 \\
(0.008)\end{array}$ & $* *$ & 0.838 & $\begin{array}{l}-0.754 \\
(0.351)\end{array}$ & $* *$ & $\begin{array}{c}0.078 \\
(0.038)\end{array}$ & $* *$ & 0.838 \\
\hline Health & $\begin{array}{c}0.760 \\
(0.019)\end{array}$ & $* * *$ & $\begin{array}{c}0.028 \\
(0.013)\end{array}$ & ** & 0.773 & $\begin{array}{l}-0.341 \\
(0.195)\end{array}$ & * & $\begin{array}{c}0.252 \\
(0.093)\end{array}$ & *** & 0.773 \\
\hline Finance & $\begin{array}{c}1.094 \\
(0.030)\end{array}$ & $* * *$ & $\begin{array}{c}0.065 \\
(0.031)\end{array}$ & $* *$ & 0.922 & $\begin{array}{l}-0.125 \\
(0.073)\end{array}$ & $*$ & $\begin{array}{c}0.082 \\
(0.039)\end{array}$ & $* *$ & 0.922 \\
\hline Other & $\begin{array}{c}0.965 \\
(0.031)\end{array}$ & $* * *$ & $\begin{array}{c}0.000 \\
(0.012)\end{array}$ & & 0.919 & $\begin{array}{l}-0.044 \\
(0.048)\end{array}$ & & $\begin{array}{c}0.013 \\
(0.014)\end{array}$ & & 0.919 \\
\hline
\end{tabular}

***, **, and ${ }^{*}$ denote significance at the $1 \%, 5 \%$ and $10 \%$ levels respectively. 
Table 4

Variation in estimated market risk premium and news sentiment coefficients

This table presents the standard deviation of coefficients for 250-day rolling regressions of the form specified in Eq. (2); where returns on the specified industries are regressed on the four factor Fama French model and aggregated industry-specific news sentiment measures. Beta refers to the coefficient of the market risk premium. Estimated coefficients for the whole sample period are reported for comparative purposes. Sample Period: 250-day rolling samples (equivalent to 1-year of trading days) for the period 02 Jan 2004 - 31 Dec 2010.

\begin{tabular}{lcccc}
\hline & $\begin{array}{c}\text { Standard deviation of beta } \\
\text { coefficient for rolling 250- } \\
\text { day estimations }\end{array}$ & $\begin{array}{c}\text { Standard deviation of news } \\
\text { coefficient for rolling 250- } \\
\text { day estimations }\end{array}$ & $\begin{array}{c}\text { Estimated beta } \\
\text { coefficient for whole } \\
\text { sample }\end{array}$ & $\begin{array}{c}\text { Estimated news } \\
\text { coefficient for whole } \\
\text { sample }\end{array}$ \\
\hline Consumer Non-Durables & 0.043 & 0.110 & 0.772 & 0.046 \\
Consumer Durables & 0.087 & 0.390 & 1.235 & 0.614 \\
Manufacturing & 0.063 & 0.124 & 1.143 & 0.140 \\
Energy & 0.189 & 0.557 & 1.330 & -0.072 \\
Chemicals & 0.066 & 0.346 & 0.917 & -0.005 \\
Business Equipment & 0.040 & 0.033 & 1.073 & 0.127 \\
Telecoms & 0.063 & 0.290 & 0.968 & 0.078 \\
Utilities & 0.099 & 0.927 & 0.886 & 0.043 \\
Retail & 0.079 & 0.149 & 0.858 & 0.018 \\
Health & 0.094 & 0.212 & 0.760 & 0.028 \\
Finance & 0.071 & 0.260 & 1.094 & 0.965 \\
Other & 0.040 & 0.023 & 0.065
\end{tabular}


Table 5

News sentiment and industry returns in different states of investor fear

This table presents coefficients for the regression specified in Eq. (2) where returns on the specified industries are regressed on the four factor Fama French model and aggregated industry-specific news sentiment measures. Only coefficients for the news sentiment measures are reported. For specifications (1) and (2) the sample only includes those days when investor fear is high and the level of VIX is in the top quintile, the sample for specifications (3) and (4) include all other days. Newey West standard errors are reported in brackets. Sample Period: 02 Jan 2004 - 31 Dec 2010.

\begin{tabular}{|c|c|c|c|c|c|c|c|c|c|c|c|}
\hline \multirow[b]{3}{*}{ Industry } & \multicolumn{5}{|c|}{ VIX High } & \multicolumn{6}{|c|}{ VIX Other } \\
\hline & \multirow{2}{*}{$\begin{array}{r}(1) \\
\text { News }\end{array}$} & \multicolumn{3}{|c|}{ (2) } & & \multicolumn{2}{|l|}{ (3) } & \multicolumn{4}{|c|}{ (4) } \\
\hline & & $\begin{array}{c}\text { Negative } \\
\text { News }\end{array}$ & & $\begin{array}{l}\text { Positive } \\
\text { News }\end{array}$ & & News & & $\begin{array}{c}\text { Negative } \\
\text { News }\end{array}$ & & $\begin{array}{c}\text { Positive } \\
\text { News }\end{array}$ & \\
\hline Consumer Non-Durables & $\begin{array}{c}0.334 \\
(0.178)\end{array}$ & $\begin{array}{cc}* & 0.135 \\
& (0.868)\end{array}$ & & $\begin{array}{c}0.345 \\
(0.187)\end{array}$ & * & $\begin{array}{c}0.126 \\
(0.046)\end{array}$ & *** & $\begin{array}{l}-0.364 \\
(0.474)\end{array}$ & & $\begin{array}{c}0.131 \\
(0.046)\end{array}$ & ${ }^{* * *}$ \\
\hline Consumer Durables & $\begin{array}{c}0.107 \\
(0.355)\end{array}$ & $\begin{array}{c}0.518 \\
(0.785)\end{array}$ & & $\begin{array}{l}-0.124 \\
(0.373)\end{array}$ & & $\begin{array}{c}0.520 \\
(0.136)\end{array}$ & $* * *$ & $\begin{array}{l}-1.784 \\
(0.799)\end{array}$ & $* *$ & $\begin{array}{c}0.478 \\
(0.141)\end{array}$ & $* * *$ \\
\hline Manufacturing & $\begin{array}{c}0.130 \\
(0.099)\end{array}$ & $\begin{array}{c}0.279 \\
(0.323)\end{array}$ & & $\begin{array}{c}0.121 \\
(0.104)\end{array}$ & & $\begin{array}{c}0.123 \\
(0.029)\end{array}$ & $* * *$ & $\begin{array}{l}-0.328 \\
(0.774)\end{array}$ & & $\begin{array}{c}0.123 \\
(0.030)\end{array}$ & $* * *$ \\
\hline Energy & $\begin{array}{l}-0.272 \\
(0.452)\end{array}$ & $\begin{array}{l}-0.829 \\
(0.385)\end{array}$ & $* *$ & $\begin{array}{c}0.685 \\
(0.463)\end{array}$ & & $\begin{array}{c}0.167 \\
(0.164)\end{array}$ & & $\begin{array}{l}-0.012 \\
(0.239)\end{array}$ & & $\begin{array}{c}0.223 \\
(0.203)\end{array}$ & \\
\hline Chemicals & $\begin{array}{c}0.019 \\
(0.276)\end{array}$ & $\begin{array}{l}-0.337 \\
(0.464)\end{array}$ & & $\begin{array}{c}0.132 \\
(0.309)\end{array}$ & & $\begin{array}{c}0.271 \\
(0.118)\end{array}$ & $* *$ & $\begin{array}{l}-1.051 \\
(0.742)\end{array}$ & & $\begin{array}{c}0.318 \\
(0.117)\end{array}$ & *** \\
\hline Business Equipment & $\begin{array}{c}0.026 \\
(0.036)\end{array}$ & $\begin{array}{c}-0.608 \\
(1.135)\end{array}$ & & $\begin{array}{c}0.027 \\
(0.036)\end{array}$ & & $\begin{array}{c}0.036 \\
(0.011)\end{array}$ & *** & $\begin{array}{l}-1.787 \\
(3.142)\end{array}$ & & $\begin{array}{c}0.036 \\
(0.011)\end{array}$ & ${ }^{* * *}$ \\
\hline Telecoms & $\begin{array}{c}0.159 \\
(0.156)\end{array}$ & $\begin{array}{c}0.233 \\
(0.803)\end{array}$ & & $\begin{array}{c}0.153 \\
(0.157)\end{array}$ & & $\begin{array}{c}0.135 \\
(0.059)\end{array}$ & $* *$ & $\begin{array}{l}-0.529 \\
(0.556)\end{array}$ & & $\begin{array}{c}0.139 \\
(0.060)\end{array}$ & ** \\
\hline Utilities & $\begin{array}{c}0.667 \\
(1.597)\end{array}$ & $\begin{array}{l}-9.800 \\
(4.03)\end{array}$ & ** & $\begin{array}{c}3.139 \\
(2.414)\end{array}$ & & $\begin{array}{c}0.172 \\
(0.070)\end{array}$ & $* *$ & $\begin{array}{l}-0.089 \\
(1.186)\end{array}$ & & $\begin{array}{c}0.182 \\
(0.088)\end{array}$ & ** \\
\hline Retail & $\begin{array}{c}0.059 \\
(0.122)\end{array}$ & $\begin{array}{l}-1.630 \\
(1.306)\end{array}$ & & $\begin{array}{c}0.147 \\
(0.085)\end{array}$ & $*$ & $\begin{array}{c}0.068 \\
(0.032)\end{array}$ & ${ }^{* *}$ & $\begin{array}{l}-0.231 \\
(0.425)\end{array}$ & & $\begin{array}{c}0.067 \\
(0.033)\end{array}$ & ** \\
\hline Health & $\begin{array}{c}0.307 \\
(0.211)\end{array}$ & $\begin{array}{c}0.361 \\
(0.384)\end{array}$ & & $\begin{array}{c}0.299 \\
(0.231)\end{array}$ & & $\begin{array}{c}0.242 \\
(0.065)\end{array}$ & $* * *$ & $\begin{array}{l}-0.253 \\
(0.179)\end{array}$ & & $\begin{array}{c}0.241 \\
(0.069)\end{array}$ & $* * *$ \\
\hline Finance & $\begin{array}{c}0.203 \\
(0.270)\end{array}$ & $\begin{array}{l}-1.771 \\
(1.682)\end{array}$ & & $\begin{array}{c}0.252 \\
(0.279)\end{array}$ & & $\begin{array}{c}0.074 \\
(0.034)\end{array}$ & $* *$ & $\begin{array}{l}-0.349 \\
(0.752)\end{array}$ & & $\begin{array}{c}0.048 \\
(0.016)\end{array}$ & *** \\
\hline Other & $\begin{array}{l}-0.030 \\
(0.026) \\
\end{array}$ & $\begin{array}{l}-0.147 \\
(0.059) \\
\end{array}$ & & $\begin{array}{c}0.003 \\
(0.028) \\
\end{array}$ & $* *$ & $\begin{array}{c}0.014 \\
(0.006) \\
\end{array}$ & & $\begin{array}{l}-0.047 \\
(0.033) \\
\end{array}$ & ${ }^{* * *}$ & $\begin{array}{c}0.013 \\
(0.006) \\
\end{array}$ & ** \\
\hline
\end{tabular}

${ }^{* * *},{ }^{* *}$, and ${ }^{*}$ denote significance at the $1 \%, 5 \%$ and $10 \%$ levels respectively. 
Table 6

News sentiment and cross section of returns

This table presents coefficients for the regression specified in Eq. (2) where returns on the specified portfolios are regressed on the four factor Fama French model and aggregated news sentiment measures. Only coefficients for the news sentiment measures are reported. Newey West standard errors are reported in brackets. Sample Period: 02 Jan 2004 - 31 Dec 2010.

(1)

All News
(2)

Negative News

\begin{tabular}{|c|c|c|c|c|c|c|}
\hline \multirow{2}{*}{\multicolumn{7}{|c|}{ 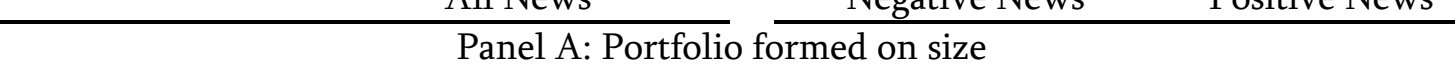 }} \\
\hline & & & & & & \\
\hline 1 (low) & 0.016 & $(0.011)$ & -0.070 & $(0.117)$ & 0.018 & ${ }^{*} \quad(0.011)$ \\
\hline 2 & 0.055 & ${ }^{* * *}(0.007)$ & -0.215 & *** $(0.085)$ & 0.061 & ${ }^{* * *}(0.007)$ \\
\hline 3 & 0.073 & ${ }^{* * *}(0.011)$ & -0.174 & $(0.109)$ & 0.069 & ${ }^{* * *}(0.012)$ \\
\hline 4 & 0.075 & ${ }^{* * *}(0.013)$ & -0.115 & $(0.173)$ & 0.074 & ${ }^{* * *}(0.013)$ \\
\hline 5 (high) & 0.081 & ${ }^{* * *}(0.003)$ & -0.175 & *** $(0.055)$ & 0.075 & ${ }^{* * *}(0.003)$ \\
\hline \multicolumn{7}{|c|}{ Panel B: Portfolio formed on book-to-market } \\
\hline 1 (low) & 0.063 & ${ }^{* * *}(0.008)$ & -0.267 & *** $(0.092)$ & 0.056 & ${ }^{* * *}(0.008)$ \\
\hline 2 & 0.054 & ${ }^{* * *}(0.011)$ & -0.241 & $*(0.140)$ & 0.061 & ${ }^{* * *}(0.001)$ \\
\hline 3 & 0.025 & ** $(0.012)$ & -0.246 & $*(0.143)$ & 0.032 & ** $(0.013)$ \\
\hline 4 & 0.031 & ** $(0.013)$ & -0.068 & $(0.171)$ & 0.033 & ** $(0.013)$ \\
\hline 5 (high) & 0.059 & ${ }^{* * *}(0.017)$ & -0.249 & $*(0.136)$ & 0.076 & ${ }^{* * *}(0.017)$ \\
\hline \multicolumn{7}{|c|}{ Panel C: Portfolio formed on basis of size and book-to-market } \\
\hline Small-Value & 0.049 & *** $(0.008)$ & -0.048 & $(0.083)$ & 0.051 & ${ }^{* * *} \quad(0.008)$ \\
\hline Small-Neutral & 0.045 & ${ }^{* * *}(0.008)$ & -0.288 & *** $(0.076)$ & 0.053 & ${ }^{* * *} \quad(0.008)$ \\
\hline Small-Growth & 0.036 & ${ }^{* * *}(0.007)$ & -0.209 & ${ }^{* *} \quad(0.106)$ & 0.042 & ${ }^{* * *}(0.011)$ \\
\hline Big-Value & 0.040 & ${ }^{* * *}(0.012)$ & -0.243 & ${ }^{* *} \quad(0.118)$ & 0.049 & ${ }^{* * *}(0.012)$ \\
\hline Big-Neutral & 0.038 & ${ }^{* * *}(0.010)$ & -0.219 & ${ }^{* *} \quad(0.108)$ & 0.039 & ${ }^{* * *}(0.010)$ \\
\hline Big-Growth & 0.035 & ${ }^{* * *}(0.007)$ & -0.079 & $(0.083)$ & 0.058 & ${ }^{* * *} \quad(0.007)$ \\
\hline \multicolumn{7}{|c|}{ Panel D: Portfolio formed on basis of size and momentum } \\
\hline Small-Up & 0.042 & ${ }^{* * *}(0.013)$ & -0.279 & $(0.220)$ & 0.066 & ${ }^{* * *}(0.013)$ \\
\hline Small-Medium & 0.050 & ${ }^{* * *}(0.010)$ & -0.155 & $(0.109)$ & 0.055 & ${ }^{* * *}(0.009)$ \\
\hline Small-Down & 0.058 & *** $(0.013)$ & -0.279 & $(0.220)$ & 0.066 & ** $(0.013)$ \\
\hline Big-Up & 0.065 & ${ }^{* * *}(0.012)$ & -0.188 & $(0.147)$ & 0.071 & ${ }^{* * *}(0.012)$ \\
\hline Big-Medium & 0.033 & ${ }^{* * *}(0.009)$ & -0.262 & $*(0.142)$ & 0.039 & ${ }^{* * *} \quad(0.009)$ \\
\hline Big-Down & 0.048 & ${ }^{* * *}(0.016)$ & -0.135 & $(0.263)$ & 0.053 & ${ }^{* * *} \quad(0.015)$ \\
\hline
\end{tabular}

${ }^{* * *},{ }^{* *}$, and ${ }^{*}$ denote significance at the $1 \%, 5 \%$ and $10 \%$ levels respectively. 